\title{
Feasibility Study of Ferromagnetic Cores Fabrication by Addi- tive Manufacturing Process
}

\author{
Giulia Stornelli ${ }^{1}$, Paolo Folgarait ${ }^{2}$, Maria Rita Ridolfi ${ }^{2}$, Domenico Corapi ${ }^{2}$, Christian Repitsch ${ }^{3}$, Orlando Di \\ Pietro ${ }^{4}$ and Andrea Di Schino ${ }^{4}$
}

Citation: Stornelli, G.; Folgarait, P.; Ridolfi, M.R.; Corapi, D.; Repitsch, C.; Pietro, O.D.; Schino, A.D. Feasibility Study of Ferromagnetic Cores Fabrication by Additive Manufacturing Process. 2021, $1, x$. https://doi.org/10.3390/xxxxx

Published: date

Publisher's Note: MDPI stays neutral with regard to jurisdictional claims in published maps and institutional affiliations.

\section{Copyright: (c) 2021 by the authors.} Submitted for possible open access publication under the terms and conditions of the Creative Commons Attribution (CC BY) license (http://creativecommons.org/licenses/by/4.0/).

\author{
${ }^{1}$ Dipartimento di Ingegneria industriale, Università degli studi di Roma "Tor Vergata", via del Politecnico 1, \\ 00133 Roma, Italy; giulia.stornelli@students.uniroma2.eu (G.S) \\ 2 Seamthesis Srl, Via IV Novembre 156, 29122 Piacenza, Italy; paolo.folgarait@seamthesis.com (P.F.); mari- \\ arita.ridolfi@seamthesis.com (M.R.R.), domenico.corapi@seamthesis.com (D.C.) \\ ${ }^{3}$ M4P Material Solutions GmbH, Gewerbestraße 4, 9181 Feistritz, Austria; c.repitsch@metals4printing.com \\ (C.R.) \\ ${ }^{4}$ Dipartimento di Ingegneria, Università degli studi di Perugia, via G. Duranti, 06125 Perugia, Italy; or- \\ lando.dipietro@studenti.unipg.it (O.D.P.), andrea.dischino@unipg.it (A.D.S.) \\ * Correspondence:
}

\begin{abstract}
Currently, the commercial production of ferromagnetic cores involves staking thin sheets of soft magnetic material, alternating with dielectric material to reduce the eddy current losses. High silicon FeSi steels show excellent soft magnetic properties. Anyway, their workability decreases $\mathrm{Si}$ content increases thus imposing a technological limit in the production of thin sheets up to $3.5-4 \%$ Si. The additive manufacturing (AM) process based on laser powder bed fusion (L-PBF) offers the possibility to redesign the magnetic components, compared to conventional design, allowing to act on the chemical composition of magnetic materials and on the geometry of the components. In the case of FeSi alloys, the additive technology allows to overcome the limit of Si content opening new perspectives for the production of ferromagnetic cores with high magnetic performance. In this work the feasibility study on the production of FeSi magnetic steel components by L-PBF technology is reported. Two variants of FeSi steels, with Si content of $3.0 \mathrm{wt} \%$ and $6.5 \mathrm{wt} \%$, were considered. The effect of process parameters on the densification of manufactured parts was investigated. The best operating window has been identified for both steel chemical compositions, in terms of laser scan speed and power.
\end{abstract}

Keywords: additive manufacturing; FeSi steels; magnetic properties

\section{Introduction}

The increasing adoption of electrical components has led to realize electrical machines with increasing performances: in particular, electric motors, electric generators, electric transformers, and inductive filters are nowadays more and more required. The possibility to develop and produce machines able to convert energy in an economically convenience way is strongly dependent on several aspects: among this aspect the adoption of high performing magnetic materials is of primarily importance [1-2].

When talking about materials, Silicon steels represent one of the most important classes of soft magnetic materials used in magnetic applications [3-5]. In more detail it is worth to be mentioned that FeSi steels with Si content ranging $2 \mathrm{wt}$ \% and $7 \mathrm{wt} . \%$, are able to guarantee excellent electromagnetic proprieties [6] coupled a proper electrical resistivity [7]: following to that, they are commonly adopted as reference materials for ferromagnetic cores of electrical motors, generators, electrical transformers, etc. [8].

The commonly adopted process aimed to produce ferromagnetic is based on the superposition of FeSi thin foils coated by a dielectric material [1]: this will allow to inhibit the induced currents circulation path thus reducing eddy current losses [9]. Such a process 
provides an evident technological limits, as a matter of fact FeSi steel with 6.5 wt.\% Si offers the best soft magnetic proprieties [10] such as: high magnetic saturation, low magneto-crystalline anisotropy, low magnetostriction and, above all, high electrical resistivity [11]. Nonetheless, silicon steels with $\mathrm{Si}$ content higher than $4.5 \%$ are intrinsically brittle: following to their low workability, it is not possible to cold reduce them down to thickness values $(0.30-0.60 \mathrm{~mm})$ required by the above reported process [12].

The brittleness of the high Si steels is mainly based on their ability to form phases with ordered structures during cooling $[13,14]$. It is known that the dislocations movement into an ordered structure forms antiphase boundaries [15]: this will lead to an hardness increase an therefore in a ductility reduction [15] with consequent low temperature workability loss [8].

Following to that, some alternative processes have been investigated aimed to build up parts other-ways not suitable to be produced by conventional route (e.g. [16]): rapid quenching route capability has been exploited prevent the order-disordered phase transition [17]; chemical vapor deposition (CVD) [18] has been also exploited aimed to deposit Si by thermal diffusion over low Si content coils. Other process routes include direct powder rolling, strip casting, physics vapor deposition (PVD) or spray forming [19]. All these techniques appeared to be too expensive to be industrially challenging: therefore they are nowadays considered of poor practical application.

For many years, the Additive Manufacturing (AM) has been imposing itself as a solid technology to produce metallic materials components on industrial scale. Among these, the Fe-based alloys plays a strategic role [20]. In the last years, it has been recognized the role played by $\mathrm{AM}$ as a foreseeing alternative route for magnetic FeSi components manufacturing of high Si contents are considered [9]. Currently, the most widespread AM technology, in industrial applications, is the Powder Bed Fusion (PBF). The PBF technology mainly uses the laser source as an energy source. The components are manufactured by laser melting metal powders [21], directly from Computer Aided Design (CAD) models [22]. The high cooling rates involved in the laser melting process allow to avoid the typical disordered-ordered phase transition in FeSi steels. This also will allow to ferromagnetic cores geometry optimization.

Even if the scientific research on magnetic materials and components by means of Additive Manufacturing technology is quite young, the possibility to produce even more complex and performing components represents a goal towards an innovative class of materials for ferromagnetic cores able to meet the challenging requests from the electric traction sector and, in general, from electric propulsion transport [23].

The present paper reports about the use the Direct Melting Laser Sintering (DMLS) technology to manufacture ferromagnetic cores with high Si content with high performances, providing a competitive alternative for industrial applications. In particular, results of a feasibility study for the production of FeSi steels through Direct Melting Laser Sintering (DMLS) technology are reported. Two FeSi steels have been considered with Si content of 3.0 and $6.5 \mathrm{wt} . \%$ and the metallurgical characteristics in relation to the process technological parameters.

\section{Materials and Methods}

Two FeSi steels with Si content of 3.0 and 6.5 wt.\% have been considered. The powders were produced by gas-atomization and their chemical compositions (wt.\%) are reported in Table 1.

Table 1. Chemical composition (wt.\%) of the as-received powders of FeSi3 and FeSi6.5 steels used in L-PBF system.

\begin{tabular}{ccccc}
\hline & Fe & Si & C & O \\
\hline FeSi3 & Bal. & 3.0 & 0.009 & 0.0001 \\
\hline
\end{tabular}




\begin{tabular}{lllll}
\hline FeSi6.5 & Bal. & 6.5 & 0.008 & 0.0001 \\
\hline
\end{tabular}

Particles size distributions measured by laser diffraction methods (Mastersizer 3000, Malvern-Panalytical), show average sizes of about $31 \mu \mathrm{m}$ and $25 \mu \mathrm{m}$ for FeSi3 and FeSi6.5 steel powders, respectively. The powders were processed through a system with L-PBF technology to produce test samples. The fabrication was carried out in an EOS M290 machine equipped with a $\mathrm{Yb}$ fiber laser with a nominal diameter of $100 \mu \mathrm{m}$ and a Gaussian power distribution curve. The platform temperature was kept at $200^{\circ} \mathrm{C}$, the maximum temperature allowed by the device, aimed to residual stresses induced by thermal gradients minimization. The process was carried out under an Argon atmosphere (oxygen content below $0.4 \%)$. Twenty cubes $(11 \mathrm{~mm} \times 11 \mathrm{~mm} \times 11 \mathrm{~mm})$ of both steels were manufactured in order to analyse the process parameters effect on the component density. The use of a proprietary simulation model developed for the L-PBF process [24] allowed to calculate the fusion process main characteristics for this class of materials. The model describes the interaction, on a microscopic scale between metal powder, laser source, and as mixture within the process chamber and allows to define the laser specific energy $E\left(\mathrm{Jm}^{-1}\right)$ range $\left(150-400 \mathrm{Jm}^{-1}\right)$ where it is possible to investigate the regimes of the fusion process by 'conduction' and by 'keyhole'. The values of scan speed $v$ and laser power $P$ were varied, respectively, in the ranges $0.5-1 \mathrm{~ms}^{-1}$ and $75-240 \mathrm{~W}$. The set of parameters $(v, P$ and $E)$ investigated for the laser melting process are reported in detail in Table 1.

Table 1. Investigated process parameters window to fabricate the twenty cubic samples of both FeSi3 and FeSi6.5 steels.

\begin{tabular}{ccccccccccc}
\hline & S1 & S2 & S3 & S4 & S5 & S6 & S7 & S8 & S9 & S10 \\
\hline$E\left[\mathbf{J m}^{-1}\right]$ & 150 & 150 & 200 & 200 & 225 & 250 & 250 & 275 & 275 & 275 \\
$\boldsymbol{v}\left[\mathbf{m s}^{-1}\right]$ & 0.5 & 1 & 0.835 & 0.5 & 0.75 & 0.668 & 1 & 0.5 & 0.607 & 0.942 \\
$\boldsymbol{P}[\mathbf{W}]$ & 75 & 150 & 167 & 100 & 168.8 & 167 & 250 & 137.5 & 167 & 259 \\
\hline & $\mathbf{S 1 1}$ & $\mathbf{S 1 2}$ & $\mathbf{S 1 3}$ & $\mathbf{S 1 4}$ & $\mathbf{S 1 5}$ & $\mathbf{S 1 6}$ & $\mathbf{S 1 7}$ & $\mathbf{S 1 8}$ & $\mathrm{S19}$ & $\mathbf{S 2 0}$ \\
\hline $\boldsymbol{E}\left[\mathrm{Jm}^{-1}\right]$ & 300 & 300 & 300 & 310 & 325 & 325 & 325 & 350 & 350 & 400 \\
$\boldsymbol{v}\left[\mathbf{m s}^{-1}\right]$ & 0.557 & 0.863 & 1 & 0.7 & 0.514 & 0.797 & 1 & 0.5 & 0.74 & 0.6 \\
$\boldsymbol{P}[\mathbf{W}]$ & 167 & 259 & 300 & 217 & 167 & 259 & 325 & 175 & 259 & 240 \\
\hline
\end{tabular}

The scan line spacing thickness of each powder layer were kept constant $(60 \mu \mathrm{m}$ and $30 \mu \mathrm{m})$, according to [9] and [13], and the samples were built with a scanning strategy which turned the laser direction $67^{\circ}$ at each layer. The density of the cubic samples was determined using the Archimedes method (AB54 Mettler Toledo). The samples were weighed first in air and then in distilled water in the suspension state as a counter-proof. The measurements were performed three times for each sample and the relative density was expressed as the average value. The samples were cut along a plane parallel to the built direction (BD), and analysed by an optical microscope (Eclipse LV150NL, Nikon) to evaluate the presence and the nature of porosities and cracks, related to the process parameters. The same polished surfaces were etched a solution of $2 \%$ Nital for $20-40 \mathrm{~s}$ to observe the morphology of the meltpool and the solidification microstructure.

\section{Results and discussion}

The relative density values of the cubic samples as obtained based on the process parameters reported in Table 1 are shown in Table 2 and Table 3 for FeSi3 and FeSi6.5 steels, respectively. Results showed that $E=250 \mathrm{Jm}^{-1}, v=1 \mathrm{~ms}^{-1}, P=250 \mathrm{~W}$ is the best combination in order to porosity reduction in FeSi3. In particular, FeSi3 S7 sample, showed a relative density of $99.99 \%$. S3 FeSi6.5 specimen, manufactured according to $E=200 \mathrm{Jm}^{-1}$, $v=0.835 \mathrm{~ms}^{-1}, P=167 \mathrm{~W}$, reported a relative density of $99.99 \%$.

Table 2. Relative density \% of cubic samples of FeSi3 steel. The density taken as the reference was $7.68 \mathrm{gcm}^{-3}$ 


\begin{tabular}{ccccccccccc}
\hline & S1 & S2 & S3 & S4 & S5 & S6 & S7 & S8 & S9 & S10 \\
\hline $\begin{array}{c}\text { Relative } \\
\text { density [\%] }\end{array}$ & 99.936 & 99.995 & 99.995 & 99.974 & 99.996 & 99.994 & 99.997 & 99.969 & 99.991 & 99.995 \\
\hline & S11 & S12 & S13 & S14 & S15 & S16 & S17 & S18 & S19 & S20 \\
\hline $\begin{array}{c}\text { Relative } \\
\text { density [\%] }\end{array}$ & 99.994 & 99.995 & 99.993 & 99.993 & 99.986 & 99.995 & 99.991 & 99.986 & 99.994 & 99.985 \\
\hline
\end{tabular}

Table 3. Relative density \% of cubic samples of FeSi6.5 steel. The density taken as the reference was $7.44 \mathrm{gcm}^{-3}$

\begin{tabular}{ccccccccccc}
\hline & S1 & S2 & S3 & S4 & S5 & S6 & S7 & S8 & S9 & S10 \\
\hline $\begin{array}{c}\text { Relative } \\
\text { density [\%] }\end{array}$ & 99.968 & 99.998 & 99.998 & 99.993 & 99.998 & 99.997 & 99.995 & 99.991 & 99.996 & 99.996 \\
\hline & S11 & S12 & S13 & S14 & S15 & S16 & S17 & S18 & S19 & S20 \\
\hline $\begin{array}{c}\text { Relative } \\
\text { density [\%] }\end{array}$ & 99.994 & 99.996 & 99.994 & 99.993 & 99.989 & 99.996 & 99.997 & 99.983 & 99.994 & 99.981 \\
\hline
\end{tabular}

Polished sections analysis (Figure 1 and Figure 2) of FeSi3 specimens was fully cracks-free whereas all the samples of FeSi6.5 steel exhibit cracks: such defects presence was increased with specific laser energy increase. The process parameters related to the S3-FeSi6.5 sample can be considered as the best compromise in terms of sample densification and cracks formation.

Irregularly shaped pores were put in evidence by metallographic analysis in the case of low specific laser energy values (Figure 1(a) and Figure 2(a). This pores shape is associated to empty spaces among not perfectly melted powder particles. The relative density of the S1 sample was the lowest among all the samples for both steels, $99.93 \%$ and $99.96 \%$, respectively for FeSi3 and FeSi6.5. In the contrary, when a high specific laser energy is adopted, the pores assume a spherical shape (Figure 1(b) and Figure 2(b)).

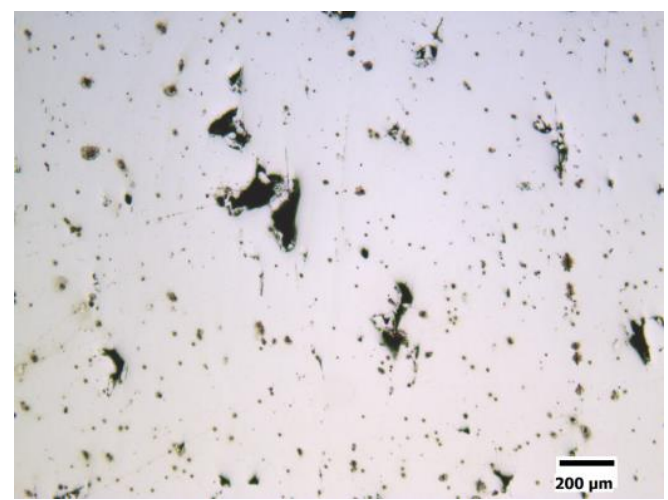

(a)

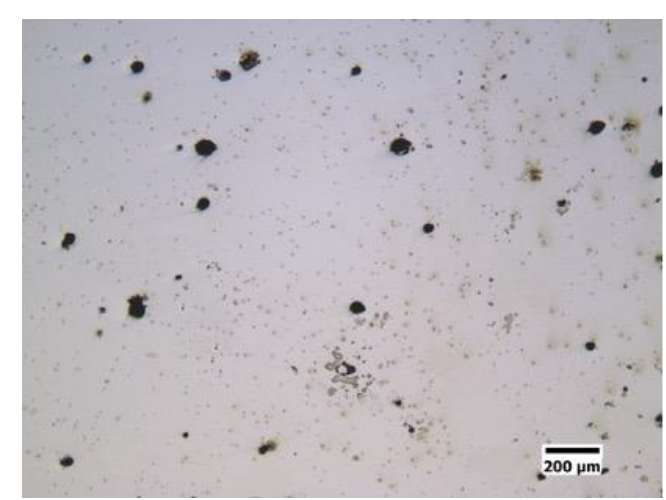

(b)

Figure 1. Specific laser energy effect $E\left[\mathrm{Jm}^{-1}\right]$ on the densification of FeSi3 steel-samples. (a) Sample $\mathrm{S} 1\left(E=150 \mathrm{Jm}^{-1}, v=0.5 \mathrm{~ms}^{-1}, P=75\right.$ $\mathrm{W})$, relative density of the sample $99.93 \%$ and pores with irregular shape. (b) Sample S18 ( $\left.E=350 \mathrm{Jm}^{-1}, v=0.5 \mathrm{~ms}^{-1}, P=175 \mathrm{~W}\right)$, relative density of the sample $99.98 \%$ and pores with spherical shape. 


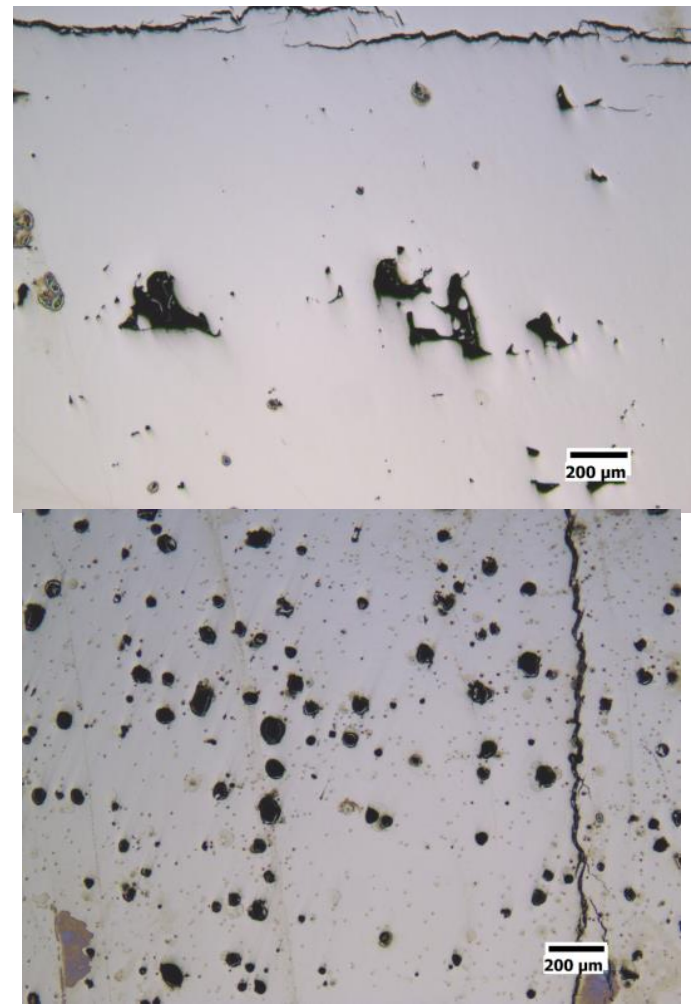

(a) (b)

Figure 2. Specific laser energy effect $\mathrm{E}\left[\mathrm{Jm}^{-1}\right]$ on the densification of FeSi6.5 steel samples. (a) Sample $\mathrm{S} 1\left(\mathrm{E}=150 \mathrm{Jm}^{-1}, \mathrm{v}=0.5 \mathrm{~ms}^{-1}, \mathrm{P}=75 \mathrm{~W}\right)$, relative density of the sample $99.93 \%$ and pores with irregular shape. (b) Sample S18 (E=350 $\left.\mathrm{Jm}^{-1}, \mathrm{v}=0.5 \mathrm{~ms}^{-1}, \mathrm{P}=175 \mathrm{~W}\right)$, relative density of the sample $99.98 \%$ and pores with spherical shape.

The relative density of the S18 samples was $99.98 \%$ for both FeSi3 and FeSi6.5 steels. The sphericity of the pores is due metal vapor and partially ionized gas entrapment. The subsequent fast cooling freezes the spherical shape of the final cavity [25]. This type of phenomenon occurs typically when quite deep keyhole cavities are formed in the melt pool, filled with plasma from both the process gas and the metal vapor. In this regard, the transition from conduction to keyhole mode is also testified by the increasing depth of the track transverse section, observable in the sample etched surfaces. Examples are given in Figure 3(a) for the conduction mode (shallow penetration) and in Figure 3(b) for the keyhole mode (high penetration). The solidification microstructures are fully columnar as shown as an example in Figure 4(a) for the samples S7-FeSi3 sample. This microstructure is expected for FeSi steels produced by AM [9] because, on each new layer, the solidification grains grow epitaxially from the consolidated material of the underling layer. This allows the continuous growth of the columnar grains, directed parallel to the built direction of the component. A relevant result is that the fully columnar microstructure is lost in the high porosity samples. In case of lack of fusion, the interruption of the columnar growth is caused by the not complete interconnection among the tracks Figure 4(b). 


\section{BD $\uparrow$}

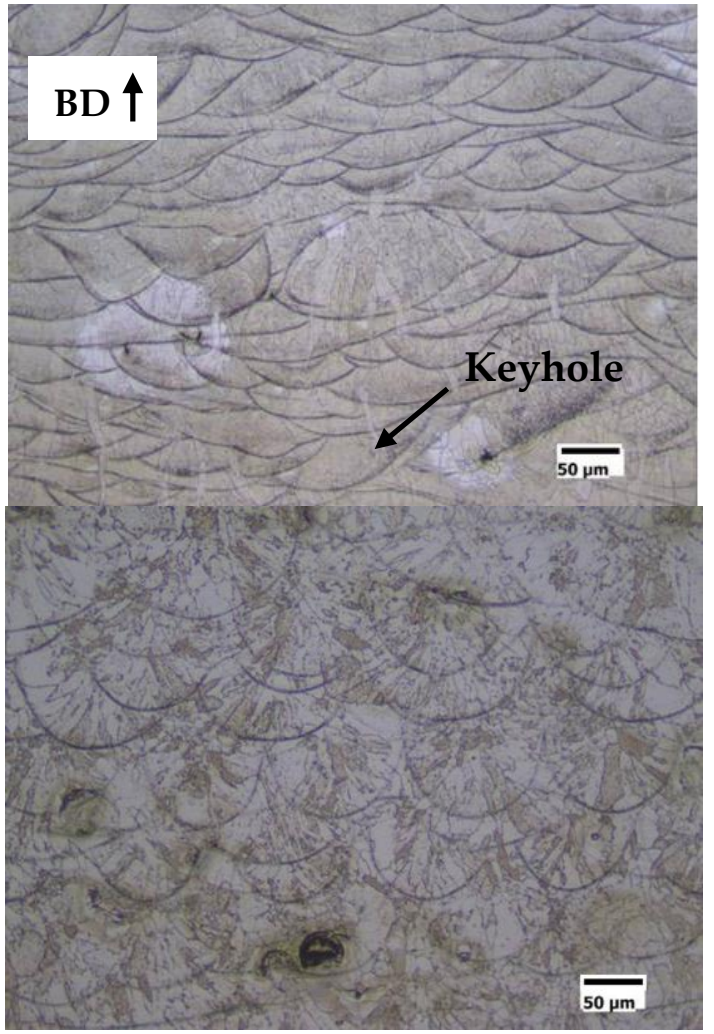

(a)

(b)

Figure 3. Example of transition from conduction melting to keyhole formation. (a) Optical micrograph of the longitudinal section to the build direction (BD) of S1-FeSi6.5 sample $\left(E=150 \mathrm{Jm}^{-1}, v=0.5 \mathrm{~ms}^{-1}, P=75 \mathrm{~W}\right)$, conduction melt mode. (b) Optical micrograph of the longitudinal section to the build direction (BD) of S18-FeSi6.5 sample ( $\left.E=350 \mathrm{Jm}^{-1}, v=0.5 \mathrm{~ms}^{-1}, P=175 \mathrm{~W}\right)$, keyhole mode.

(a)

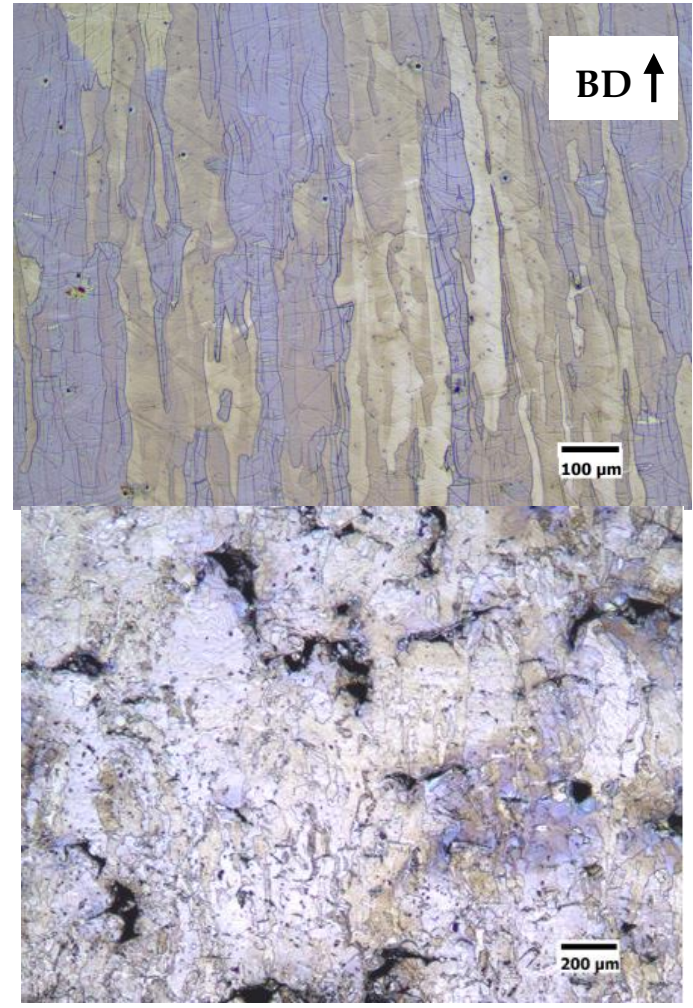

(b) 
Figure 4. (a) Example of columnar microstructure of longitudinal sections along the built direction (BD) of the highest density samples (S7-FeSi3, $E=250 \mathrm{Jm}^{-1}, v=1 \mathrm{~ms}^{-1}, P=250 \mathrm{~W}$ ). (b) Example of non-columnar microstructure in a high porosity samples (S1FeSi3, $\left.E=150 \mathrm{Jm}^{-1}, v=0.5 \mathrm{~ms}^{-1}, P=75 \mathrm{~W}\right)$

\section{Conclusions}

An experimental campaign was carried out to investigate the possibility of fabricating ferromagnetic cores of improved performances by means of L-PBF technique using an EOS M290 system and FeSi steels with 3.0 and 6.5 wt.\% Si content. The main critical issue to get high density and crack free printed parts is the very narrow range of process parameters: the porosities are caused by lack of fusion at low laser energies and keyhole onset at high energies while the cracks are due to the high thermal gradients.

At optimized operating conditions, a relative density close to 1 is obtained for both the tested steels. A fully columnar solidification microstructure along the built direction is observed, due to the epitaxial growth starting from the already consolidated material of the underlying layers.

Funding: This research work received the support of the Umbria Region (Italy), public contribution to R\&D under EU Regulation n. 651/2014 ex-Art. 25. The support by University of Perugia through its program for Basic Research 2017 and its financing through the project RICBA17FC is also gratefully acknowledged.

\section{References}

1. Krings, B.A.; Cossale, M.; Tenconi, A.; Soulard, J.; Cavagnino, A.; Boglietti, A. Magnetic Materials Used in Electrical Machines. IEEE Ind. Appl. Mag. 2017, 23, 21-28.

2. Boglietti, A.; Cavagnino, A.; Krings, A. New Magnetic Materials for Electrical Machines and Power Converters. IEEE Trans. Ind. Electron. 2017, 64, 2402-2404, doi:10.1109/TIE.2016.2630021.

3. Cardelli, E; Advances in Magnetic Hysteresis Modeling. Handb. Magn. Mater. 2015, 24, 323-409.

4. De Campos, M.F.; Teixeira, J.C.; Landgraf, F.J.G. The optimum grain size for minimizing energy losses in iron. J. Magn. Magn. Mater. 2006, 301, 94-99, doi:10.1016/j.jmmm.2005.06.014.

5. Garibaldi, M.; Ashcroft, I.; Simonelli, M.; Hague, R. Metallurgy of high-silicon steel parts produced using Selective Laser Melting. Acta Mater. 2016, 110, 207-216, doi:10.1016/j.actamat.2016.03.037.

6. Garibaldi, M.; Ashcroft, I.; Hillier, N.; Harmon, S.A.C.; Hague, R. Relationship between laser energy input, microstructures and magnetic properties of selective laser melted Fe-6.9\%wt Si soft magnets. Mater. Charact. 2018, 143, 144-151, doi:10.1016/j.matchar.2018.01.016.

7. Shokrollahi, H.; Janghorban, K. Soft magnetic composite materials (SMCs). J. Mater. Process. Technol. 2007, 189, 1-12, doi:10.1016/j.jmatprotec.2007.02.034.

8. Lemke, J.N.; Simonelli, M.; Garibaldi, M.; Ashcroft, I.; Hague, R.; Vedani, M.; Wildman, R.; Tuck, C. Calorimetric study and microstructure analysis of the order-disorder phase transformation in silicon steel built by SLM. J. Alloys Compd. 2017, 722, 293-301, doi:10.1016/j.jallcom.2017.06.085.

9. Goll, D.; Schuller, D.; Martinek, G.; Kunert, T.; Schurr, J.; Sinz, C.; Schubert, T.; Bernthaler, T.; Riegel, H.; Schneider, G. Additive manufacturing of soft magnetic materials and components. Addit. Manuf. 2019, 27, 428-439, doi:10.1016/j.addma.2019.02.021.

10. You, A.; Be, M.A.Y.; In, I. Commercial scale production of Fe-6.5 wt. \% Si sheet and its magnetic properties. Journal of Applied Physics. 1988, 64, 5367.

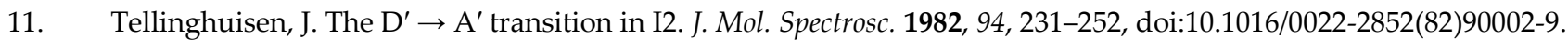

12. Ros-Yanez, T.; Ruiz, D.; Barros, J.; Houbaert, Y.; Colás, R. Study of deformation and aging behaviour of iron-silicon alloys. Mater. Sci. Eng. A 2007, 447, 27-34, doi:10.1016/j.msea.2006.10.075.

13. Viala, B.; Degauque, J.; Fagot, M.; Baricco, M.; Ferrara, E.; Fiorillo, F. Study of the brittle behaviour of annealed Fe-6.5 wt\%Si ribbons produced by planar flow casting. Mater. Sci. Eng. A 1996, 212, 62-68, doi:10.1016/0921-5093(96)10188-X.

14. Jang, P.; Lee, B.; Choi, G. Effects of annealing on the magnetic properties of Fe-6.5\%Si alloy powder cores. J. Appl. Phys. 2008, 103, 5-8, doi:10.1063/1.2839620.

15. González, F.; Houbaert, Y. A review of ordering phenomena in iron-silicon alloys. Rev. Metal. 2013, 49, 178-199, doi:10.3989/revmetalm.1223.

16. Li, R.; Shen, Q.; Zhang, L.; Zhang, T. Magnetic properties of high silicon iron sheet fabricated by direct powder rolling. J. Magn. Magn. Mater. 2004, 281, 135-139, doi:10.1016/j.jmmm.2004.04.098.

17. Tsuya, N.; Shimanaka, H.; Kan, T. Ribbon-form silicon-iron alloy containing around 6\% silicon. IEEE Trans. Magn. 1980, 16, 728-733, doi:10.1109/TMAG.1980.1060692. 
18. Tian, G.; Bi, X. Fabrication and magnetic properties of Fe-6.5\% Si alloys by magnetron sputtering method. J. Alloys Compd. 2010, 502, 1-4, doi:10.1016/j.jallcom.2010.02.175.

19. Fenineche, N.E.; Cherigui, M.; Aourag, H.; Coddet, C. Structure and magnetic properties study of iron-based thermally sprayed alloys. Mater. Lett. 2004, 58, 1797-1801, doi:10.1016/j.matlet.2003.11.009.

20. Di Schino, A. Manufacturing and application of stainless steels. Metals (Basel). 2020, 10, 327, doi: 10.3390/met10030327.

21. Savolainen, J.; Collan, M. How Additive Manufacturing Technology Changes Business Models? - Review of Literature. Addit. Manuf. 2020, 32, 101070, doi:10.1016/j.addma.2020.101070.

22. Sutton, A.T.; Kriewall, C.S.; Leu, M.C.; Newkirk, J.W.; Brown, B. Characterization of laser spatter and condensate generated during the selective laser melting of $304 \mathrm{~L}$ stainless steel powder. Addit. Manuf. 2020, 31, 100904, doi:10.1016/j.addma.2019.100904.

23 Wrobel, R.; Mecrow, B. A Comprehensive Review of Additive Manufacturing in Construction of Electrical Machines. IEEE Trans. Energy Convers. 2020, 35, 1054-1064, doi:10.1109/TEC.2020.2964942.

24. Ridolfi, M.R.; Folgarait, P.; Di Schino, A. Laser operating windows prediction in selective laser-melting processing of metallic powders: Development and validation of a computational fluid dynamics-based model. Materials (Basel). 2020, 13, 1424, doi:10.3390/ma13061424.

25. Narendra, B. D.; Sandip, .P.H.; Laser Fabrication and Machining of Materials, 1st ed.; Springer, 2008. 